\title{
Rigidified Dendritic Structures for Imprinting Chiral Information
}

\author{
Sharon M. Voshell and Michel R. Gagné* \\ Department of Chemistry, University of North Carolina at Chapel Hill, Chapel Hill, \\ North Carolina 27599-3290
}

\section{Supporting Information}

Typical procedure for determining the Boltzmann Distribution of the AM1 calculated conformers in Figure 2.

\begin{tabular}{|c|c|c|c|c|}
\hline Conformer & $\begin{array}{c}E \\
(\mathrm{kcal} / \mathrm{mol})\end{array}$ & $\Delta \mathrm{E}(\mathrm{kcal} / \mathrm{mol})$ & Boltzmann & Percentage \\
\hline C10 & -32.79 & 0.00 & 1.0000 & 28.53 \\
\hline C17 & -32.44 & 0.35 & 0.5912 & 16.87 \\
\hline C21 & -32.18 & 0.61 & 0.3987 & 11.38 \\
\hline C14 & -31.94 & 0.85 & 0.2772 & 7.91 \\
\hline $\mathrm{C} 27$ & -31.80 & 0.99 & 0.2248 & 6.41 \\
\hline $\mathrm{C} 22$ & -31.61 & 1.18 & 0.1687 & 4.81 \\
\hline $\mathrm{C} 24$ & -31.55 & 1.24 & 0.1538 & 4.39 \\
\hline C1 & -31.47 & 1.32 & 0.1367 & 3.90 \\
\hline C40 & -31.29 & 1.50 & 0.1036 & 2.96 \\
\hline C6 & -31.12 & 1.67 & 0.0806 & 2.30 \\
\hline $\mathrm{C} 26$ & -31.03 & 1.77 & 0.0694 & 1.98 \\
\hline C15 & -30.91 & 1.88 & 0.0581 & 1.66 \\
\hline C9 & -30.90 & 1.89 & 0.0574 & 1.64 \\
\hline C7 & -30.84 & 1.95 & 0.0524 & 1.50 \\
\hline C8 & -30.58 & 2.21 & 0.0353 & 1.01 \\
\hline C30 & -30.28 & 2.51 & 0.0224 & 0.64 \\
\hline $\mathrm{C} 20$ & -30.26 & 2.54 & 0.0217 & 0.62 \\
\hline C29 & -29.80 & 2.99 & 0.0110 & 0.31 \\
\hline C36 & -29.78 & 3.01 & 0.0106 & 0.30 \\
\hline $\mathrm{C} 28$ & -29.61 & 3.18 & 0.0082 & 0.23 \\
\hline C39 & -29.41 & 3.38 & 0.0061 & 0.17 \\
\hline C37 & -29.36 & 3.43 & 0.0056 & 0.16 \\
\hline C43 & -29.32 & 3.48 & 0.0052 & 0.15 \\
\hline C41 & -28.97 & 3.82 & 0.0031 & 0.09 \\
\hline C32 & -28.52 & 4.27 & 0.0016 & 0.05 \\
\hline C31 & -28.52 & 4.27 & 0.0016 & 0.04 \\
\hline C42 & -27.34 & 5.45 & 0.0003 & 0.01 \\
\hline & & Boltzmann Sum & 3.5051 & \\
\hline
\end{tabular}


Boltzmann $=\mathrm{e}^{(-\Delta \mathrm{E} / \mathrm{kT})}$

$\mathrm{kT}=\left(1.381 \times 10^{-23} \mathrm{~J} / \mathrm{K}\right)(333 \mathrm{~K})\left(6.022 \times 10^{23} \mathrm{~mol}^{-1}\right)(4184 \mathrm{kcal} / \mathrm{J})=0.6617 \mathrm{kcal} / \mathrm{mol}$

Percentage $=($ Boltzmann $/$ Boltzmann Sum $) * 100$






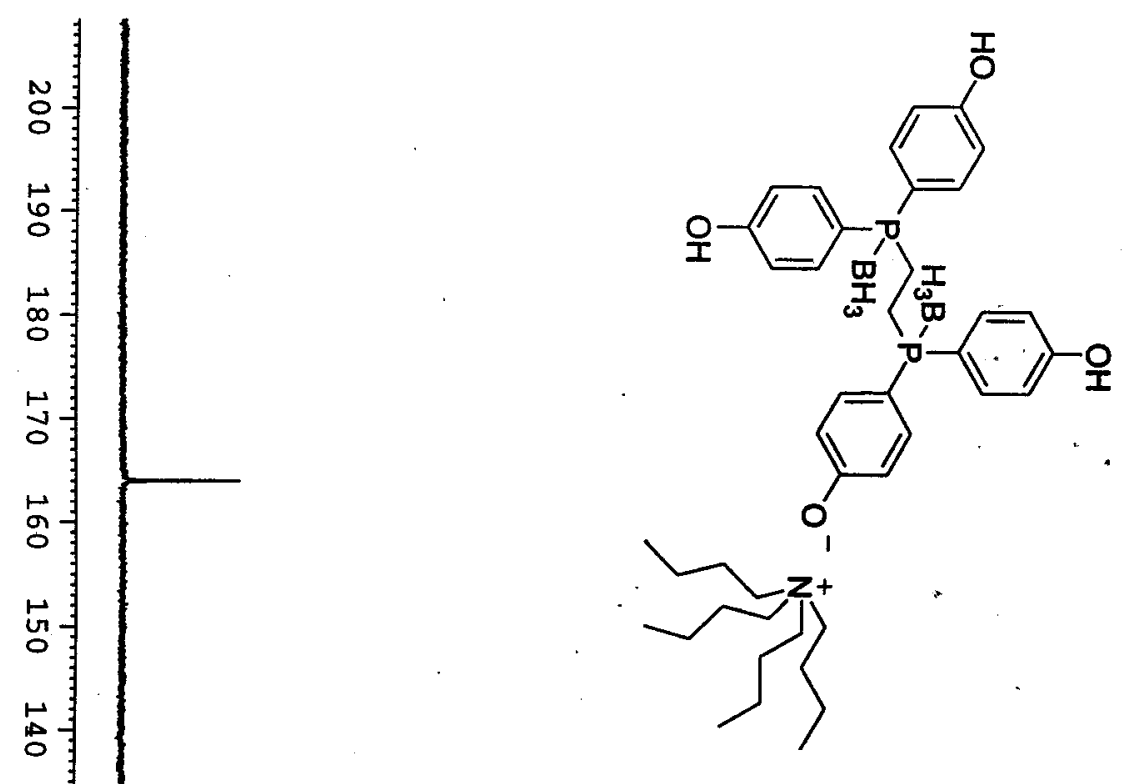

$\stackrel{\leftrightarrow}{\omega}$

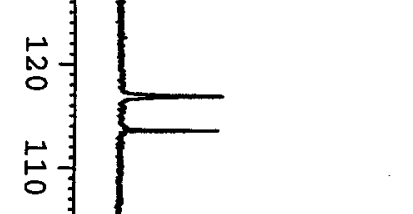

133.293

동

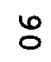

$\infty$

ํ.

응


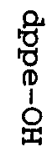
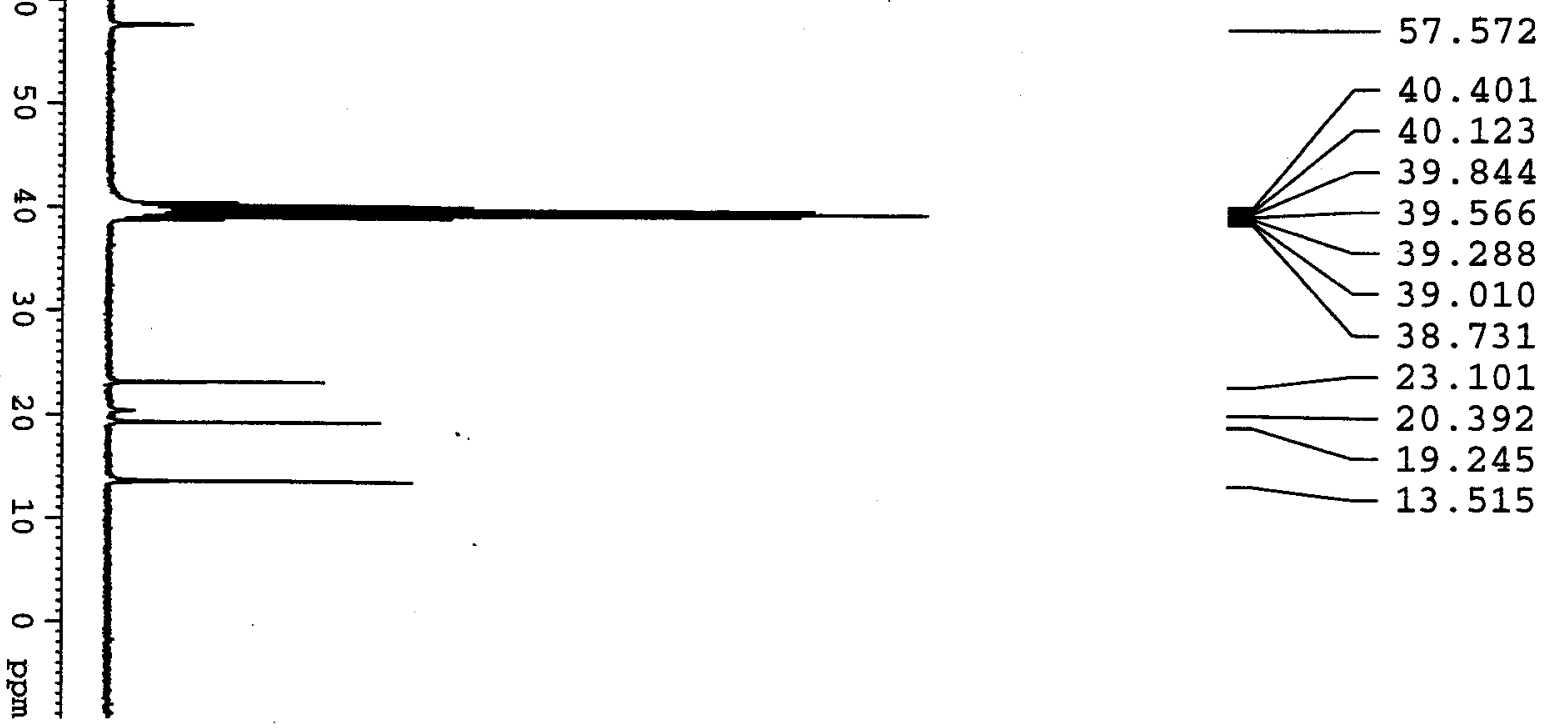



ㅇํㅇ

6

$\infty$

0

o

v

$\stackrel{\circ}{\circ}$

$\omega$

N

占

年录 